\title{
THE GENUS CORINNA (ARANEAE, CLUBIONIDAE) IN PANAMA
}

\author{
By Arthur M. Chickering \\ Museum of Comparative Zoology, Harvard University
}

In 1937 I reported five species of the genus Corinna from Barro Colorado Island, Panama Canal Zone as follows: Corinna bulbosa F. P.-Cambridge, C. crassipalpis Chickering, C. mucronata F. P.Cambridge, C. robusta Chickering, C. silvatica Chickering. These were all identified from my collection of 1934. Since that date numerous specimens of Corinna have accumulated as a result of of several additional field trips in Panama. These are all being placed in the Museum of Comparative Zoology. While preparing these specimens for integration into the collections I have identified several species not recognized in 1937. Four of these appear to represent new species. As a result of my study of all specimens now available I believe that I am able to report a total of twelve species of the genus Corinna now known from Panama. These may be listed as follows: $C$. bulbosa F. P.-Cambridge; $C$. bulbula F. P.Cambridge; $C$. casueta sp. nov.; C. crassipalpis Chickering; C. grassima sp. nov.; C. luteomaculata Petrunkevitch; C. mucronata F. P.-Cambridge; $C$. nervosa F. P.-Cambridge; $C$. perida sp. nov.; $C$. robusta Chickering; $C$. silvatica Chickering; $C$. tenubra sp. nov. Six of these are known from both sexes, four are known only from males and the remaining two are known only from females.

\section{Genus Corinna C. L. Koch, I 842}

During my study of this genus from Panama I have found that males have quite distinctive tibial and tarsal palpal features with little variation among individuals of a species. Females, however, appear to have only obscurely distinctive epigynal features and with a rather high degree of variation among specimens of a single species. It is my opinion that a thorough revisional study of the whole genus is needed.

\section{Corinna bulbosa F. P.-Cambridge Figures I-6}

Corinna bulbosa F. P.-Cambridge, 1899: 67, figs. 3-4. Male and female types are in the British Museum (Natural History). Petrunkevitch, 1911: 464; 1925: 75, 156; Banks, 1929: 58; Chickering, 1937: 22; Roewer, 1954: 595; Bonnet, 1956: 1209.

Corinna eutypa Chamberlin, 1925: 222. The female holotype from Barro Colorado Island, Panama Canal Zone is in the Museum of Comparative Zoology, examined. 
The author of this species had specimens of both sexes from Teapa, Mexico and Guatemala. Dr. Petrunkevitch first reported the species from Panama in 1925. Banks first identified Corinna eutypa Chamberlin as a synonym of Corinna bulbosa F. P.-Cambridge. In 1937 I had several specimens of both sexes from Barro Colorado Island, Panama Canal Zone.

At the present time the collection in the Museum of Comparative Zoology includes many specimens of both sexes from the following localities in the Panama Canal Zone: Barro Colorado Island, Balboa, Canal Zone Forest Preserve, Madden Dam region, Gamboa. The collection also includes both sexes from Panama outside of the Canal Zone as follows: El Valle, Porto Bello. This species appears to be the most abundant of any of the species from Panama.

Among the many specimens available for study I have noted considerable variation in color pattern. The epigynum varies considerably; some females show no spermathecae; in some others these organs are relatively small; in still other specimens they are relatively large. Some specimens show a fairly well delineated dorsal, abdominal scutum but in some other individuals there is little or no evidence of the feature. The palpal features of males seem to occur with little or no important variations. Figures I-6 illustrate what I consider to be the most important features of the male palp and some of the variations in appearance of the epigynum.

\section{Corinna perida sp. nov.}

\section{Figure 7}

Holotype. The female holotype is from Barro Colorado Island, Panama Canal Zone, July 7, 1936. The name of the species is an arbitrary combination of letters.

Description. Total length, including extended chelicerae and spinnerets, nearly $12 \mathrm{~mm}$. Carapace nearly $4.8 \mathrm{~mm}$ long, nearly $4.18 \mathrm{~mm}$ wide opposite second coxae where it is widest; nearly $1.78 \mathrm{~mm}$ tall; gently arched from PME to just above anterior end of well exposed median thoracic groove; with descent from that region to posterior border; union of thoracic and cephalic regions well marked. Eyes: eight in two rows as usual in the genus; viewed from above, posterior row gently procurved and anterior row nearly straight; viewed from in front, anterior row gently procurved. Central ocular quadrangle only slightly wider in front than behind and only slightly wider in front than long. Ratio of eyes AME : ALE : PME : PLE $=$ nearly $16:$ I2 $:$ I I : II.5. Lateral eyes quite oval; long axes used for measurements. AME separated from one another by slightly more than their radius and separated from ALE 


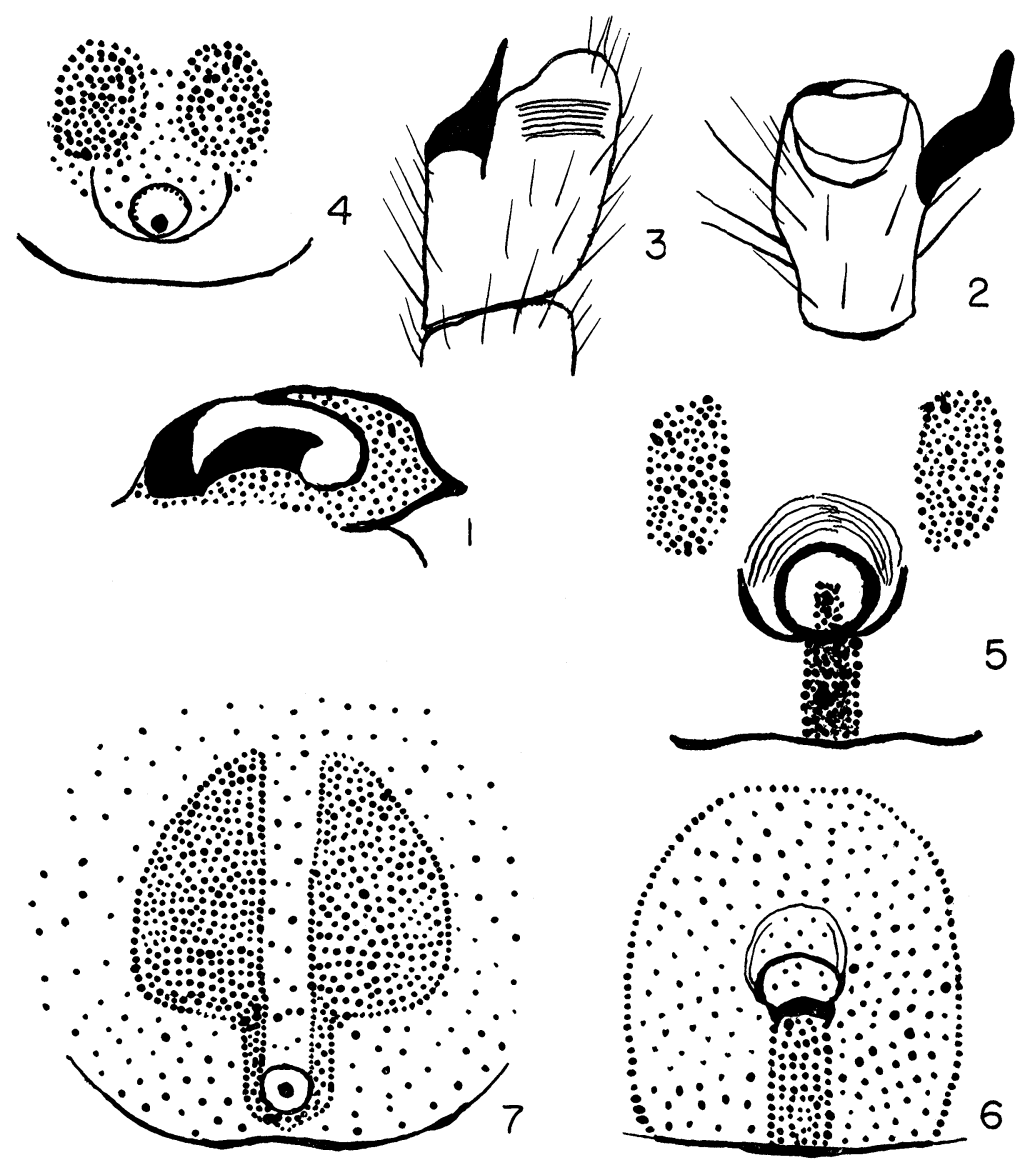

Figures 1-6. Corinna bulbosa F. P.-Cambridge. Fig. 1. Distal end of left palpal tarsal bulb removed from cymbium. Figs. 2-3. Left palpal tibia; prolateral and retrolateral views, respectively. Figs. 4-6. Epigyna from below showing variation in appearance. Figure 7. Corinna perida sp. nov.; epigynum of holotype from below. 
by slightly less than their diameter. PME separated from one another by nearly I.5 times their diameter and from PLE by nearly 2.5 times their diameter. Laterals separated by nearly seven-twelfths of the diameter of ALE. Height of clypeus nearly equal to $\mathrm{I} .33$ times the diameter of AME. Chelicerae: much extended; dorsally gibbous as usual near base; fang typical of the genus; promargin of the fang groove with four teeth and retromargin also with four teeth, first small. Maxillae: convergent but not meeting; essentially typical of the genus. Lip: slightly wider near middle than long; slightly more than half as long as maxillae. Sternum: typical of the genus in general; moderately convex; longer than wide in ratio of nearly 23 : I9; surface finely granulate; anterior border nearly straight. Legs: 4I23 in order of length; all legs with occasional spines but none are conspicuous. Abdomen: quite typical of females of the genus; without observed special modifications; with no dorsal scutum. Epigynum: moderately distinctive (Fig. 7). Color in alcohol: carapace and chelicerae as usual in the genus, a rich, dark, reddish brown with few variations; sternum a light yellowish brown; legs and other mouth parts yellowish brown with variations; abdomen a purplish brown dorsally and dorsolaterally; venter yellowish; spinnerets light yellowish; irregular, small, whitish spots at posterior end of dorsum.

Diagnosis. This species seems to be closely related to Corinna bulbosa F. P.-Cambridge and Corinna robusta Chickering. The characters of the epigynum are sufficient to establish it as a new species. Efforts to match this specimen with one of the unmatched males have been unsuccessful.

Records. No paratypes have appeared in the collection and the male is unknown.

\section{Corinna casueta sp. nov.}

Figures 8-10

Holotype. The male holotype is from Barro Colorado Island, Panama Canal Zone, July 4, I954. The name of the species is an arbitrary combination of letters.

Figures 8-10. Corinna casueta sp. nov. Fig. 8. Left palpal tarsus; ventral view. Fig. 9. Left palpal patella and tibia; retrolateral view. Fig. 10. Distal end of left palpal femur; nearly prolateral view. Figures 11-16. Corinna grassima sp. nov. Fig. 11. Anterior border of sternum of holotype. Fig. 12. Distal end of left palpal tarsus; ventral view. Figs. 13-14. Left palpal tibia; nearly ventral and retrolateral views, respectively. Figs. 15-16. Epigyna of described female paratype and second female, respectively. Figure 17. Corinna crassipalpis Chickering; epigynum from below. 


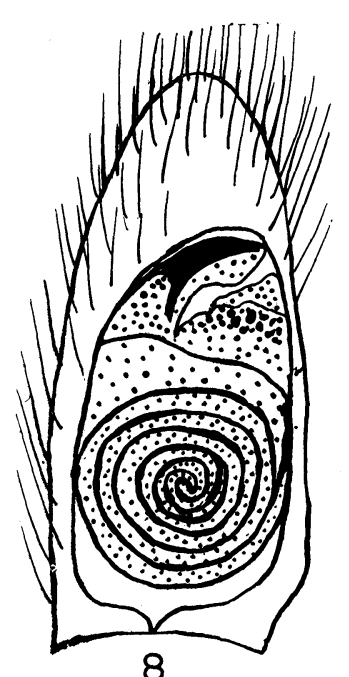

8

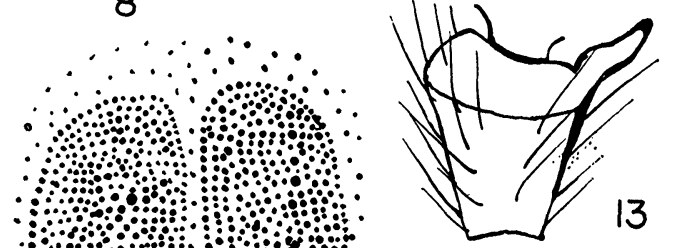

13
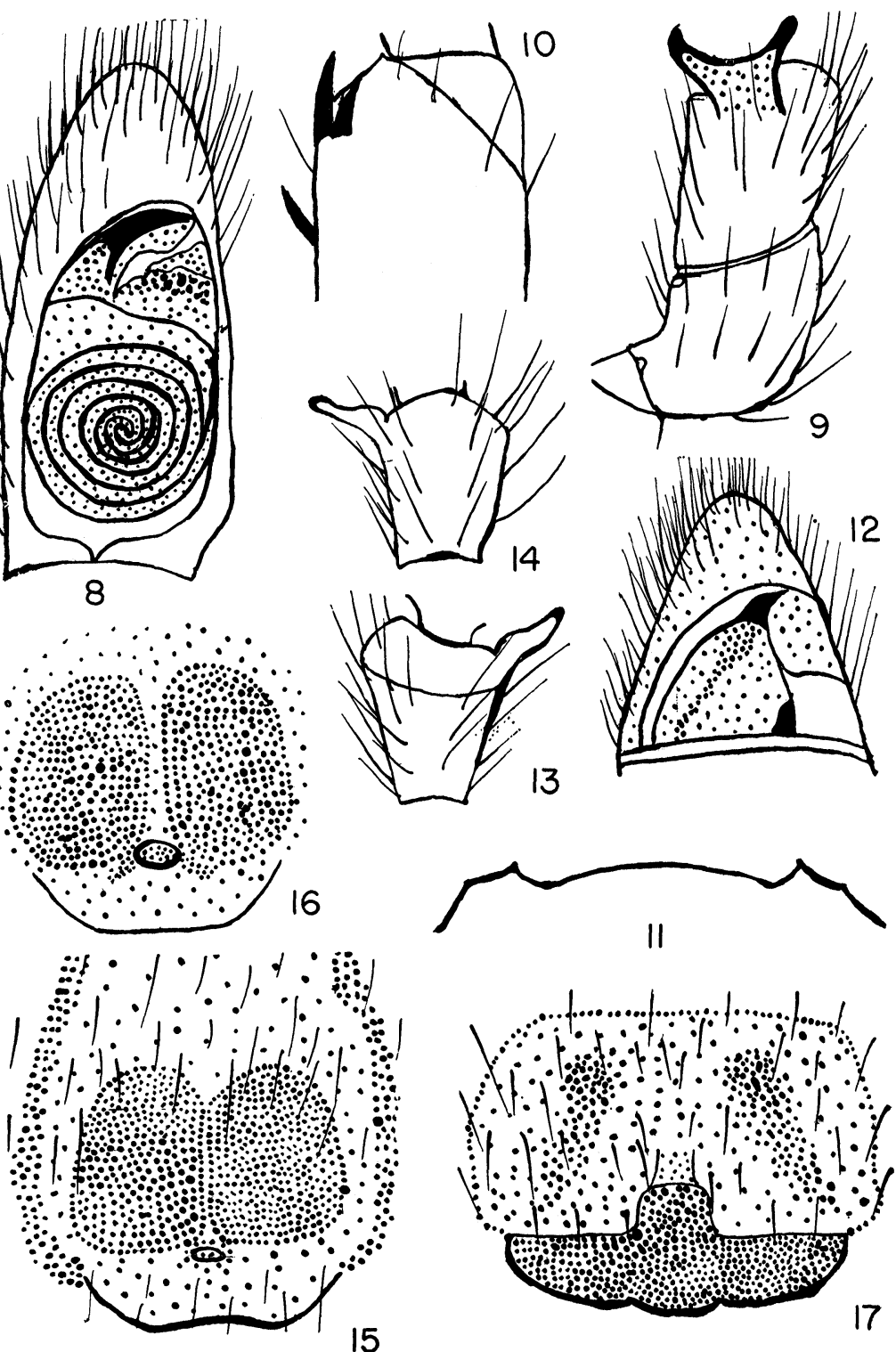
Description. Total length, including extended chelicerae, II.96 $\mathrm{mm}$. Carapace nearly $5.2 \mathrm{~mm}$ long; nearly $3.9 \mathrm{~mm}$ wide opposite second coxae where it is widest; nearly $\mathrm{I} .69 \mathrm{~mm}$ tall; arched from PME to beginning of gradually sloping posterior declivity opposite interval between second and third coxae; with a well defined median thoracic groove; with cephalic region considerably raised. Eyes: eight in two rows as usual in the genus; viewed from above, anterior row gently recurved and poster row slightly procurved; viewed from in front, anterior row gently procurved. Lateral eyes on gently raised tubercles. Height of clypeus nearly I.33 times the diameter of AME. Ratio of eyes AME : ALE : PME : PLE = $16:$ Io : IO : II. AME separated from one another by a little less than their radius and from ALE by slightly less than their diameter. PME separated from one another by nearly I.5 times their diameter and from PLE by nearly 2.7 times their diameter. Central ocular quadrangle wider in front than behind in ratio of nearly 20 : I 7 ; slightly wider in front than long. Chelicerae: robust; very gibbous dorsally at base; promargin of fang groove with three teeth and a fairly well developed scopula; the retromargin has four teeth the first of which is minute. Maxillae: convergent but not meeting beyond lip; abruptly truncate distally; with a well developed scopula. Lip: quite typical of the genus in general; widest just below middle where it is slightly wider than long. Sternum: quite typical of the genus in general; widest between second coxae; nearly four-fifths as wide as long; posterior end just opposite bases of fourth coxae which are separated by nearly one-fifth of their width. Legs: 4123 in order of length; all legs with spines. Palp: important features shown in Figures 8IO; tibial apophysis quite distinctive. Abdomen: essentially typical of males of the genus; with a very small, poorly defined, dorsal, basal scutum which is somewhat better defined in some paratypes. Color in alcohol: carapace and chelicerae a rich, dark, reddish brown; maxillae, lip, palps, legs and sternum all yellowish-brown with variations too indefinite to describe in detail; sternum finely pitted and with short, stiff hairs. The abdomen is a purplish-brown dorsally and dorsolaterally; ventrally it is light yellowish; there is a narrow, irregular purplish band ventral to the spinnerets.

Diagnosis. This species appears to be closely related to Corinna bulbosa F. P.-Cambridge and Corinna robusta Chickering now well known from the same locality. The features of the male palp definitely establish it as a new species.

Records. Three male paratypes are in the collection from the Panama Canal Zone as follows: Gatun, March 6, I958; Barro Colo- 
rado Island, August 2, 1936 and January I4, 1958. The female is unknown.

\section{Corinna grassima sp. nov.}

Figures I I-I6

Holotype. The male holotype is from Barro Colorado Island, Panama Canal Zone, May I7, 1964. The name of the species is an arbitrary combination of letters.

Description. Total length, including much extended chelicerae. $6.75 \mathrm{~mm}$. Carapace nearly $2.53 \mathrm{~mm}$ long; nearly $2.29 \mathrm{~mm}$ wide opposite interval between second and third coxae where it is widest; nearly $0.8 \mathrm{I} \mathrm{mm}$ tall; with a well defined median thoracic groove; finely serrated along ventral margin. Eyes: eight in two rows essentially as usual in the genus; viewed from above, anterior row slightly recurved and posterior row gently procurved; viewed from in front, anterior row slightly procurved. Central ocular quadrangle slightly wider behind than in front; wider behind than long in ratio of nearly 19 : 16. Ratio of eyes AME : ALE : PME : PLE = nearly $6.5: 5.5: 5: 5$. AME separated from one another by nearly their diameter and from ALE by slightly more than their radius. PME separated from one another by nearly I.6 times their diameter and from PLE by nearly twice their diameter. Lateral eyes separated from one another by nearly four-fifths of the diameter of PLE. Height of clypeus nearly equal to the diameter of AME. Chelicerae: robust; somewhat rugulose; very much extended; very gibbous dorsally near base; with well developed basal boss; promargin of right fang groove apparently with only two teeth and retromargin with five; some irregularities with teeth along left fang groove; some variations noted among paratypes. Maxillae: only slightly convergent; robust; nearly twice as long as wide; quite typical of the genus in general. Lip: about half as long as maxillae; a little wider near base than long; sternal suture procurved. Sternum: surface finely granulate; typical of the genus in general; moderately convex; longer than wide between second coxae in ratio of nearly $67: 58$; anterior margin quite distinctive (Fig. I I ; posterior end sharply pointed and reaches just opposite bases of fourth coxae which are separated by nearly 0.4 of their width; surface finely granulate and with numerous short hairs. Legs: 4I23 in order of length; all legs with spines. Palp: essential features shown in Figures I2-14; tibial apophysis simple but distinctive; bulbar canaliculus intricately convoluted essentially as in Corinna robusta Chickering and Corinna casueta sp. nov. Abdomen: essentially typical of males of the genus; with a short, rather poorly outlined dorsal, 
basal scutum. Color in alcohol: carapace and chelicerae a rich, dark, reddish brown; sternum somewhat lighter; legs with femora nearly like carapace; other segments yellowish brown with variations. Abdomen: dorsum and lateral sides a rich dark, reddish brown with numerous yellowish dots; muscle impressions yellowish; venter with book-lung areas yellowish and region between these streaked with brown; behind the genital groove the venter has three brownish stripes bordered by four narrow, irregular, yellowish stripes; spinnerets and areas at their bases nearly white; ventral area quite variable among paratypes.

Female paratype. Total length nearly $7.6 \mathrm{~mm}$. Carapace nearly $2.62 \mathrm{~mm}$ long; nearly $2.24 \mathrm{~mm}$ wide opposite second coxae where it is widest; nearly one $\mathrm{mm}$ tall shortly behind PME where it is tallest; very finely serrated along ventral margin; with a fairly well defined median, thoracic groove. The female selected for description follows the features of the male holotype so closely that a detailed description is regarded as unnecessary. The epigynum seems to be obscurely distinctive (Fig. I5). As usual in this genus, variations in the appearance of the epigynum have been noted among the females available for comparison (Fig. I6).

Diagnosis. This species appears to be another member of the group represented by Corinna robusta Chickering and Corinna bulbosa F. P.-Cambridge. The features of the male palp and the obscurely distinctive features of the female epigynum establish it as a new species.

Records. The described female paratype was taken in the same locality and at the same time as the male holotype. Both sexes are in the collection from the following localities in the Panama Canal Zone: Canal Zone Forest Preserve, August, I939; Gatun, February and March, I958; Barro Colorado Island, Corozal and Balboa, May, I964.

\section{Corinna bulbula F. P.-Cambridge}

Corinna bulbula F. P.-Cambridge, 1899: 67, figs. 2-2a. The male holotype from Bugaba, Panama is in the British Museum (Natural History). Petrunkevitch, 1911: 465 ; 1925: 75 ; Roewer, 1954: 595; Bonnet, 1956: 1210.

This species has not appeared in my collections from Panama and, as far as I have been able to determine, has not been reported since the original description was published by the author of the species.

Corinna crassipalpis Chickering Figure I7

Corinna crassipalpis Chickering, 1937: 22, figs. 15, 21, 65-66. The male 
holotype from Barro Colorado Island, Panama Canal Zone, is in the Museum of Comparative Zoology, Roewer, 1954: 596; Bonnet, 1956: 1210.

In 1937 I had only the male holotype, two female paratypes and one additional male paratype. At present the collection includes several additional males and females all from the following localities in the Canal Zone: Barro Colorado Island, Fort Randolph and Fort Sherman and all were collected in June, July and August, 1936, I939 and 1950. Figure I7 represents a clearly outlined epigynum.

\section{Corinna luteomaculata Petrunkevitch}

Corinna luteomaculata Petrunkevitch, 1925: 154, figs. 77-78. The female holotype from Cerro Flores, Panama is in the Peabody Museum, Yale University, Roewer, 1954: 598; Bonnet, 1956: 1213.

This is another species which has not appeared in my collection from Panama and is still known only from the female holotype.

\section{Corinna tenubra sp. nov.}

\section{Figures $18-22$}

Holotype. The male holotype is from Barro Colorado Island, Panama Canal Zone, June, 1950. The name of the species is an arbitrary combination of letters.

Description. Total length, including extended chelicerae, nearly $7.86 \mathrm{~mm}$. Carapace $2.93 \mathrm{~mm}$ long; nearly $2.20 \mathrm{~mm}$ wide opposite second coxae where it is widest; nearly $0.88 \mathrm{~mm}$ tall shortly behind $\mathrm{PME}$ and then slightly descending to beginning of posterior declivity opposite interval between third and fourth coxae; with a fairly well defined median thoracic groove. Eyes: eight in two rows as usual in the genus; viewed from above, anterior row moderately recurved and posterior row definitely procurved (Fig. I8). Central ocular quadrangle only slightly wider in front than behind; about as wide in front as long. Ratio of eyes AME : ALE : PME : PLE = nearly i I $: 8: 9: 8.5$. AME separated from one another by slightly more than their radius and from ALE by slightly less than their radius. PME separated from one another by nearly their diameter and from PLE by nearly I.3 times their diameter. Lateral eyes separated by nearly the radius of ALE. Height of clypeus nearly equal to the diameter of AME. Second row of eyes only slightly wider than anterior row. Chelicerae: robust; much extended; slightly divergent; teeth along fang groove not determined because of secretion and fragility of holotype. Maxillae: convergent but not meeting beyond lip; with well developed distal scopulae. Lip: slightly wider than long; slightly less than half as long as maxillae. Sternum: moderately convex; slightly lobed; nearly as wide as long; with an 


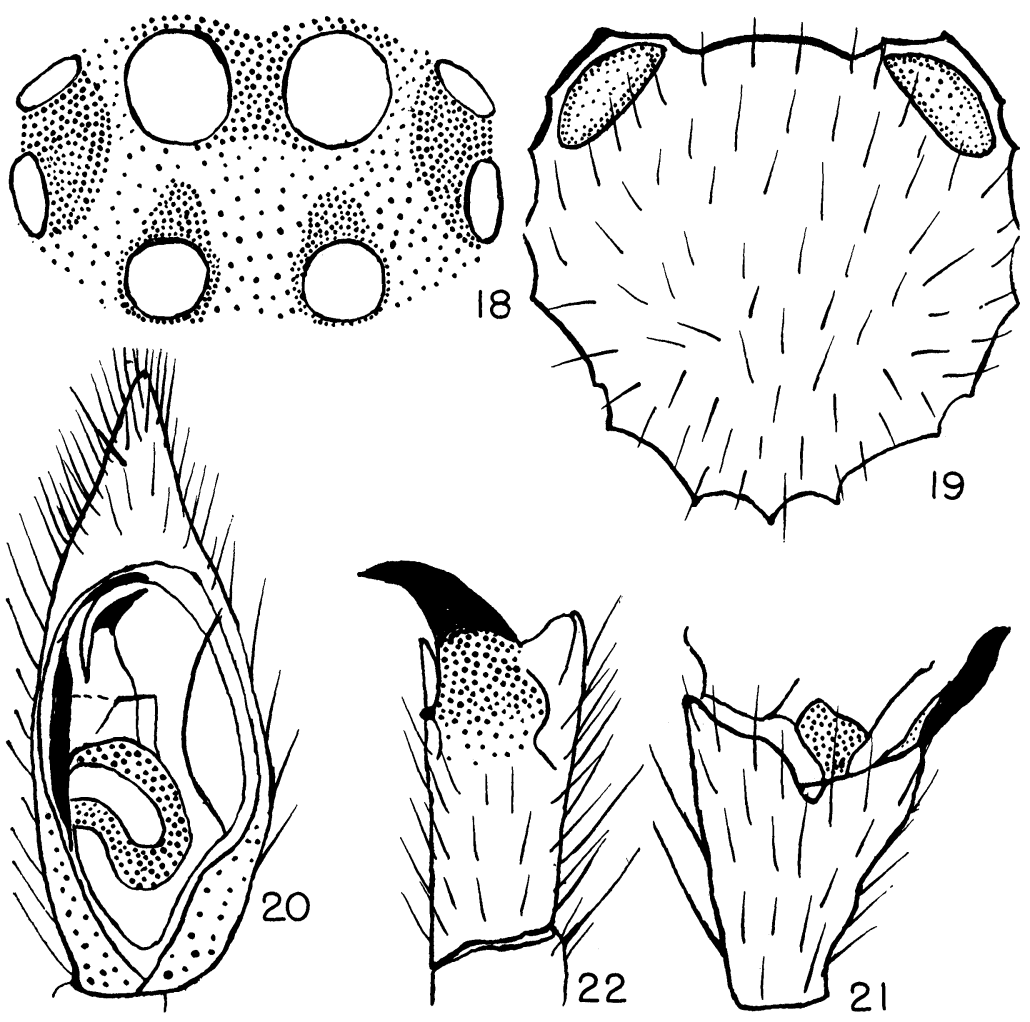

Figures 18-22. Corinna tenubra sp. nov. Fig. 18. Eyes of holotype from above. Fig. 19. Sternum of holotype from below. Fig. 20. Left palpal tarsus of holotype; ventral view. Figs. 21-22. Left palpal tibia; prolateral and retrolateral views, respectively. 
unusual concavity at each anterolateral corner (Fig. 19); posterior end sharply pointed and just opposite bases of fourth coxae which are separated by nearly one-third of their width. Legs: 4I23 in order of length; all legs with spines; typical in general of the genus. Palp: essential features shown in Figures 20-22; tarsal canaliculus simply folded, not intricately convoluted. Abdomen: all parts essentially typical of males of the genus. Color in alcohol: carapace a rich reddish brown with darker streaks radiating from region of median thoracic groove; with a moderate amount of black pigment in ocular area; chelicerae nearly like carapace; sternum a medium yellowish brown; legs light yellowish brown with some variation; abdomen generally yellowish, lighter ventrally; just dorsal to spinnerets there is a purplish area which continues dorsolaterally with diminishing clarity to base.

Diagnosis. This species seems to be most closely related to Corinna mucronata F. P.-Cambridge. The palpal features together with the unusual sternal concavities definitely establish it as a new species.

Records. There are no male paratypes and the female is unknown.

\section{Corinna mucronata F. P.-Cambridge}

Figures 23-25

Corinna mucronata F. P.-Cambridge, 1899: 69, figs. 7-8. The male holotype from Bugaba, Panama is in the British Museum (Natural History). Petrunkevitch, 1911: 467; 1925: 75; Banks, 1929: 50; Chickering, 1937: 25.

Banks (1929) reported the species from Barro Colorado Island and Fort Sherman, Panama Canal Zone. At present the collection in the Museum of Comparative Zoology includes numerous specimens of both sexes from Barro Colorado Island, July-August, I934, 1936 and 1939 together with specimens taken in May, I964. I also have collected the species in Boquete, El Valle and Porto Bello all in Panama.

There is considerable variation in size among the specimens now available for study. The sternum is quite convex and nearly as wide as long. The male palp has a complicated tibia and tarsus. There is considerable variation in the appearance of the female epigynum (Figs. 24-25).

\section{Corinna nervosa F. P.-Cambridge}

Corinna nervosa F.P.-Cambridge, 1899: 70, fig. 9. The male holotype from Guatemala or Bugaba, Panama is in the British Museum (Natural History). Petrunkevitch, 1911: 467; 1925: 76; Roewer, 1954: 598; Bonnet, 1956: 1214.

This is another species which has not been found in my collections 

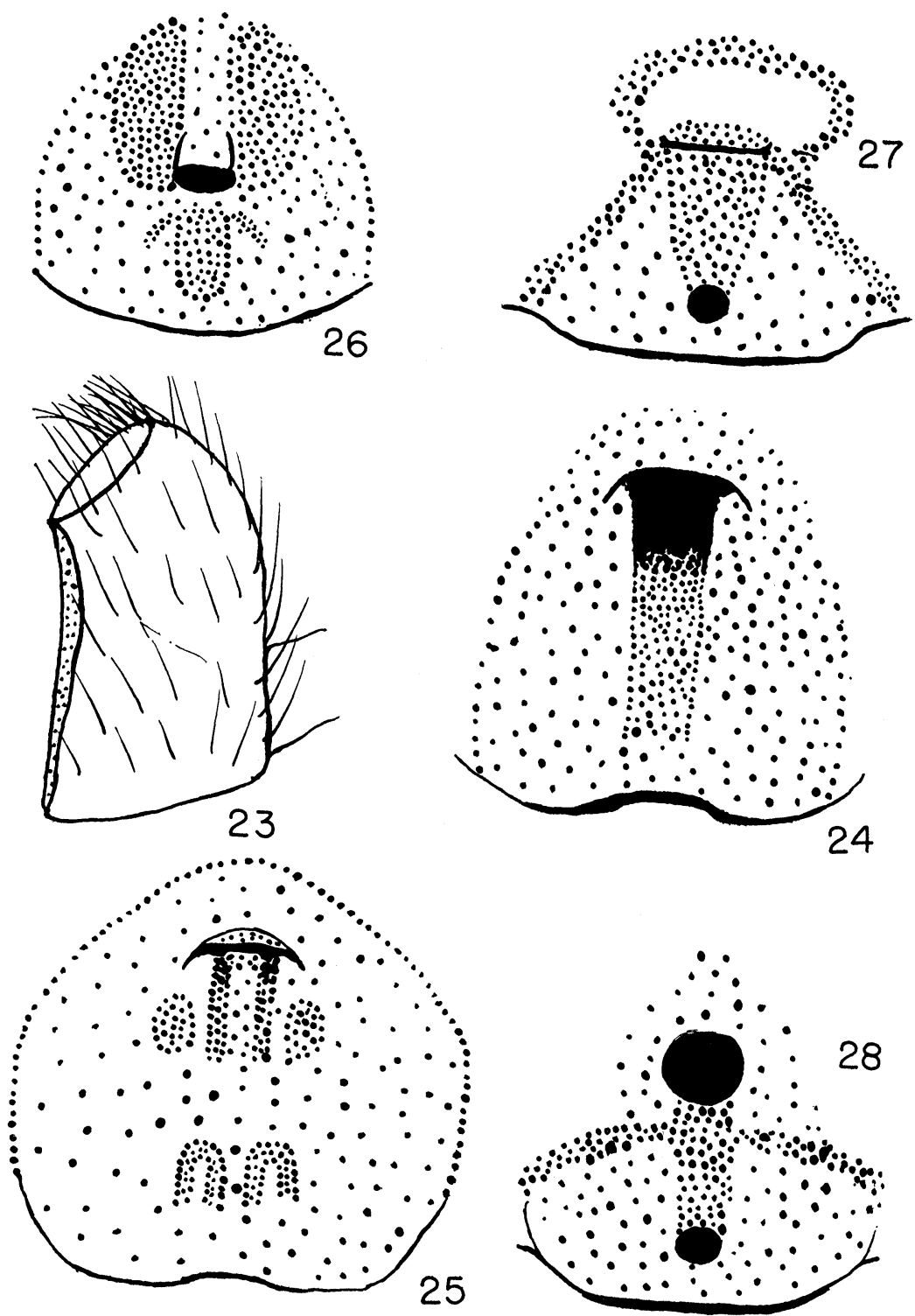
from Panama. Apparently it has not been reported since the original descriptions were published.

\section{Corinna robusta Chickering \\ Figure 26}

Corinna robusta Chickering, 1937: 25, figs. 20, 53, 75-76. The male holotype from Barro Colorado Island, Panama Canal Zone is in the Museum of Comparative Zoology. Roewer, 1954: 599; Bonnet, 1956: 1216.

In addition to the holotype and described female paratype the collection now includes one male from Barro Colorado Island, JulyAugust, I936 and two females from the same locality, June-July, 1934 and July-August, I936 together with a female from El Valle, Panama, July, 1936 and a female from Porto Bello, Panama, August, I936. The species has not been found in my collections from Panama since 1936. As usual in this genus, the epigynum varies considerably in appearance among the few specimens available for study (Fig. 26).

\section{Corinna silvatica Chickering}

Figures 27-28

Corinna silvatica Chickering, 1937: 27, figs. 9, 26, 82-83. The male holotype from Barro Colorado Island, Panama Canal Zone is in the Museum of Comparative Zoology, Roewer, 1954: 600; Bonnet, 1956: 1216.

The collection in the Museum of Comparative Zoology now includes one male, June, I950 and nine females collected June-July, 1934; June 25, I936; July-August, 1939. All are from Barro Colorado Island, Panama Canal Zone. There is considerable variation among the females regarding the appearance of the epigynum and some uncertainty exists regarding the correct identification. Figures 27-28 are offered here to show variations in appearance of this organ.

BANKs, N.

\section{BIBLIOGRAPHY}

1929. Spiders from Panama. Bull. Mus. Comp. Zool., 69: 53-96. Bonnet, Pierre

1956. Bibliographia Araneorum. Toulouse. 2(2).

Chamberlin, R. V.

1925. Diagnoses of New American Arachnida. Bull. Mus. Comp. Zool., $67(4): 211-248$.

Chickering, Arthur M.

1937. The Clubionidae of Barro Colorado Island, Panama. Trans. Amer. Micros. Soc., 56, No. 1.

Figures 23-25. Corinna mucronata F. P.-Cambridge. Fig. 23. Left maxilla of male from below. Figs. 24-25. Epigyna of females from below showing variation in appearance. Figure 26. Corinna robusta Chickering; epigynum of female from below. Figures 27-28. Corinna silvatica Chickering; epigyna of females showing variations in appearance. 
KосH, C. L.

1842. Die Arachniden. 9: 1-108. Nürnberg.

Petrunkevitch, Alexander

1911. A synonymic index-catalogue of spiders of North, Central, South America, etc. Bull. Amer. Mus. Natur. Hist., 29: 1-809.

1925. Arachnida from Panama. Trans. Connecticut Acad. Arts and Sci. 27 : 51-248.

ROEWER, C. Fr.

1954. Katalog der Araneae. 2(a). Bremen. 

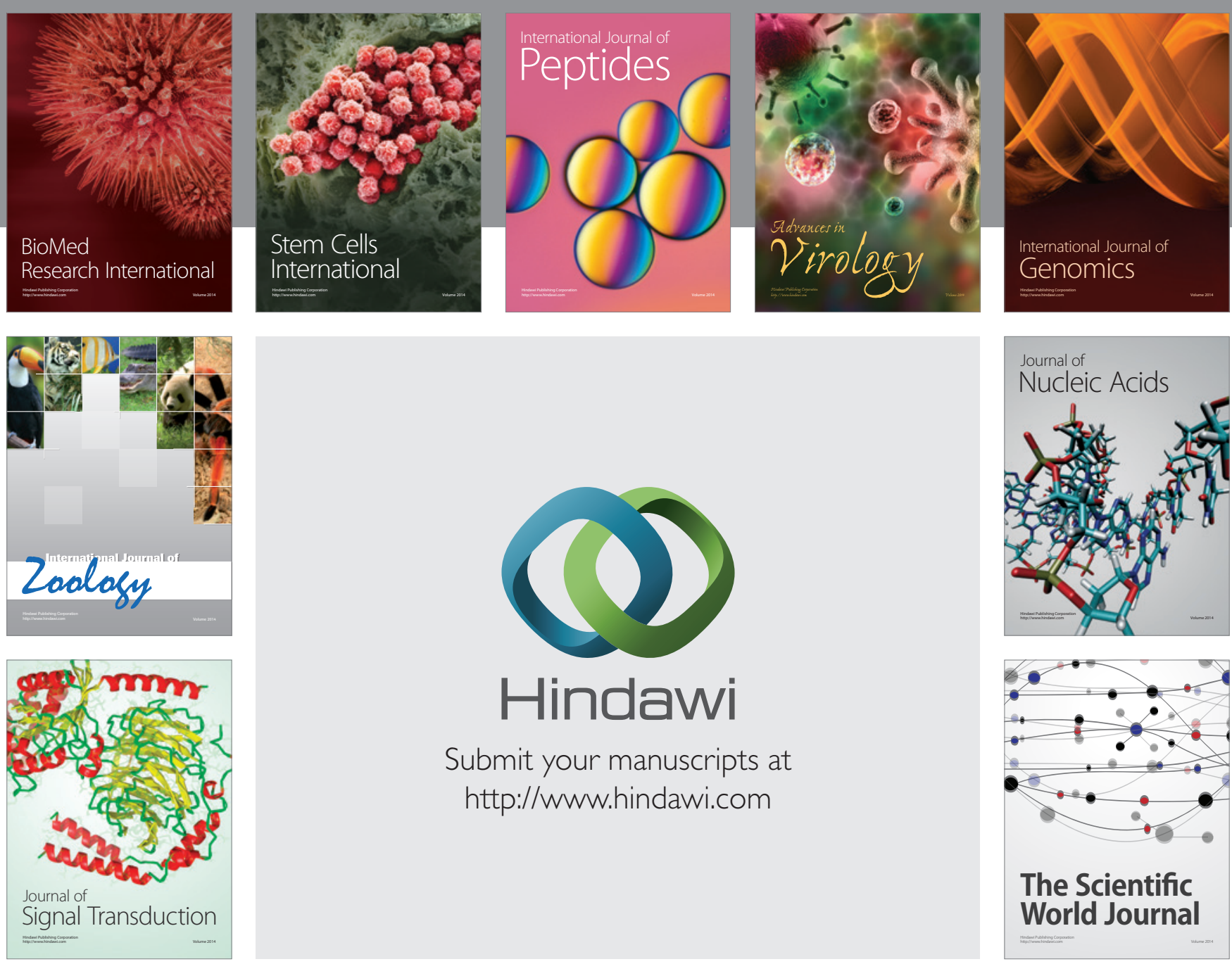

Submit your manuscripts at

http://www.hindawi.com
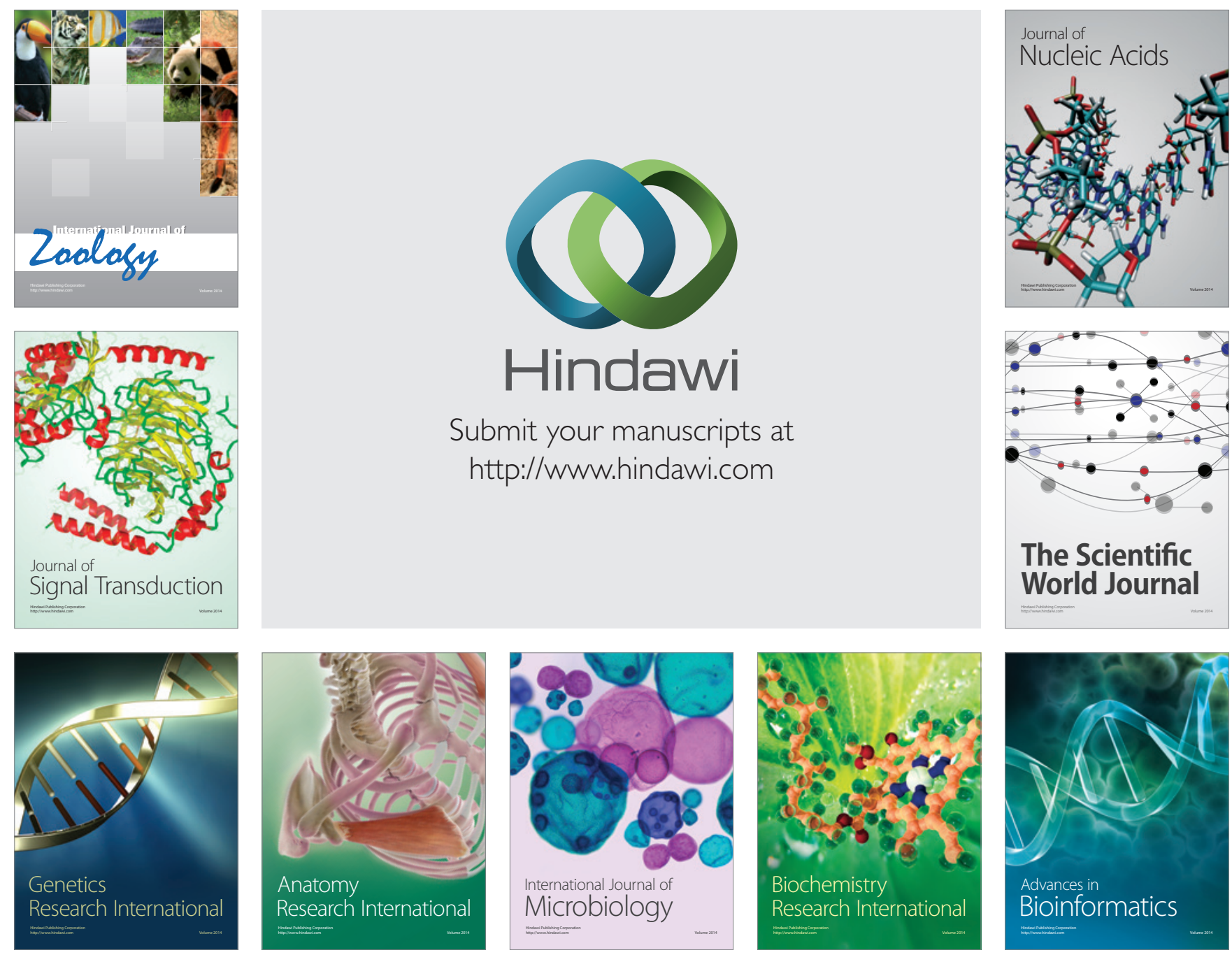

The Scientific World Journal
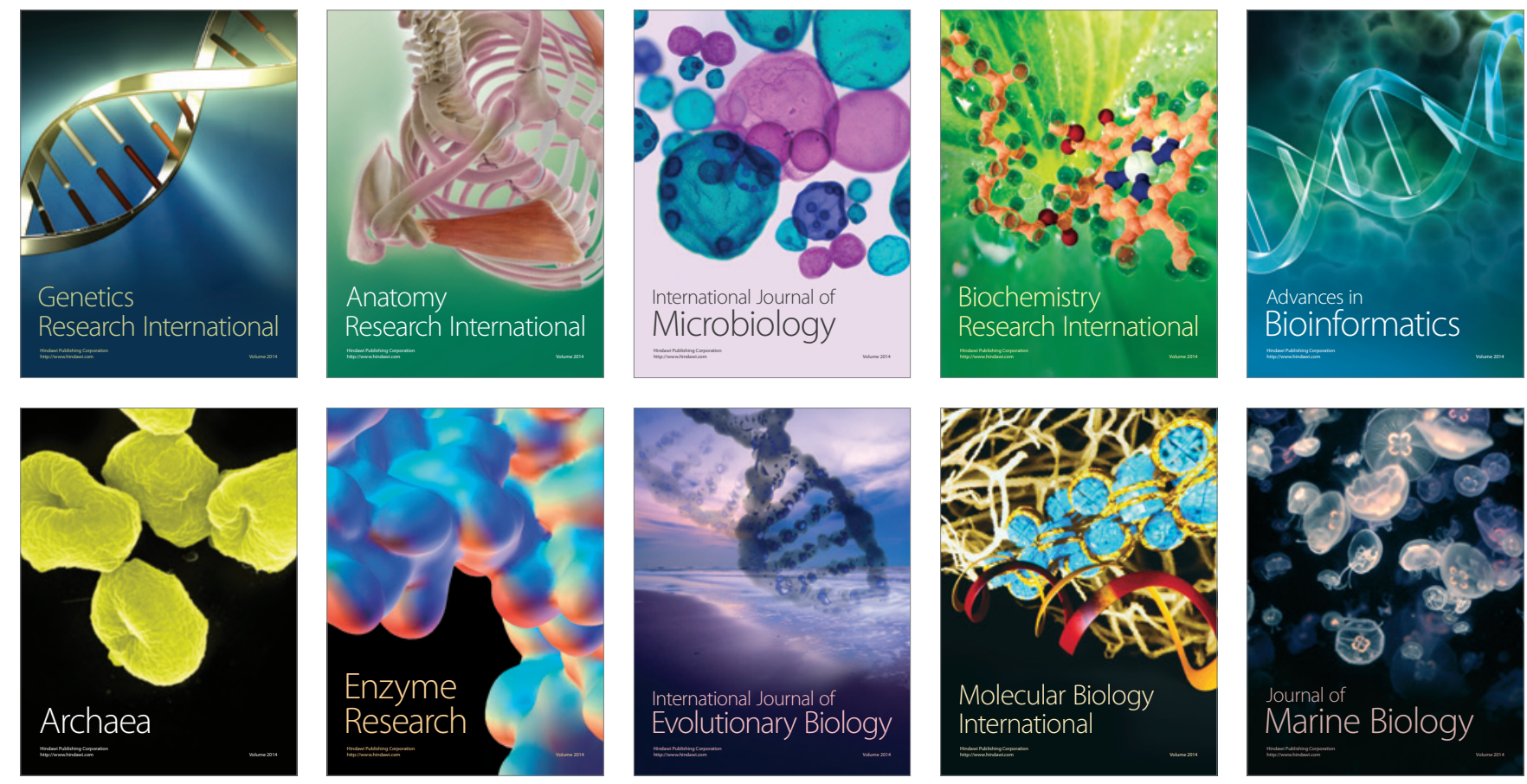